\title{
Culturas musicais contemporâneas
}

Paula Guerra e Paula Abreu

\section{(2) OpenEdition}

\section{Journals}

\section{Edição electrónica}

URL: http://journals.openedition.org/rccs/6188

DOI: $10.4000 /$ rccs.6188

ISSN: 2182-7435

\section{Editora}

Centro de Estudos Sociais da Universidade de Coimbra

Edição impressa

Data de publição: 1 maio 2016

Paginação: 5-10

ISSN: 0254-1106

\section{Refêrencia eletrónica}

Paula Guerra e Paula Abreu, « Culturas musicais contemporâneas », Revista Crítica de Ciências Sociais [Online], 109 | 2016, posto online no dia 18 maio 2016, consultado o 22 setembro 2020. URL : http:// journals.openedition.org/rccs/6188; DOI : https://doi.org/10.4000/rccs.6188 


\section{Culturas musicais contemporâneas}

A música é uma expressão cultural contemporânea que desde muito cedo foi associada a universo da produção, difusão e consumo cultural de carácter industrial. Alguns dos textos ilustrativos da teoria crítica de Adorno sobre a indústria cultural debruçam-se exatamente sobre formas industriais e populares de música. No entanto, desde os finais da década de 60 do século XX que os estudos culturais centrados no Birmingham Centre for Contemporary Cultural Studies (CCCS) têm dado conta de reconhecidas expressões musicais populares que resistem ou subvertem não apenas o mainstream da cultura musical veiculada pela indústria da música e pelos grandes meios de comunicação, mas também os universos simbólicos associados à sua produção, distribuição e consumo. Tais trabalhos apontaram a importância da música nas manifestações subculturais, mostrando a sua força agregadora e simbolizante.

Mais tarde, a partir dos anos 90 do século XX, as reações aos cultural studies, designadas como post subcultural studies ou pós-estruturalistas, têm vindo a fomentar pesquisas em torno de manifestações, produções e vivências musicais associadas a espaços específicos, a grupos geracionais e a filiações de gostos particulares. Destes advém um manancial de questões em torno da pluralidade das cenas musicais e das neotribos no mundo contemporâneo. A atual profusão de paradigmas interpretativos é bem sintomática da contínua importância da música na modelação das identidades e das memórias grupais e coletivas. A fragmentação e erosão dos géneros e subgéneros musicais, a diluição das fronteiras artísticas canónicas, a multiplicação de consumos associados à música, a ambivalência dos estatutos da produção e do consumo musical, assim como a profusão de canais de difusão e acesso à música são tendências que continuam a colocar a música, sobretudo a de carácter popular, no cerne das controvérsias culturais.

Este número temático ${ }^{1}$ da Revista Crítica de Ciências Sociais abre um espaço de discussão sobre alguns dos novos desafios colocados às culturas musicais

\footnotetext{
${ }^{1}$ Este número foi organizado em articulação com o projeto de investigação KISMIF - Keep it Simple, Make it Fast!', cofinanciado por fundos nacionais através da Fundação para a Ciência e a Tecnologia (PTDC/CS-SOC/118830/2010) e por fundos FEDER (através do programa operacional COMPETE). O KISMIF está a ser desenvolvido no Instituto de Sociologia da Faculdade de Letras
} 
contemporâneas e à forma como estes ameaçam ou estimulam o seu potencial de resistência, diferenciação e inovação face às tendências e movimentos culturais populares dominantes, continuadamente atravessados pelos efeitos da tecnologia e do (novo) espírito do capitalismo.

O conjunto de artigos que o número congrega é ilustrativo da diversidade destas mesmas questões. Neles encontramos abordagens sobre a ambivalência do potencial simbólico e identitário da música, colocando-a não apenas em relação com subculturas específicas, mas também na mediação e associação a estilos de vida partilhados e na gestão das identidades individuais; ou ainda como ingrediente fundamental na definição da singularidade de projetos especificos, sejam eles de carácter mais popular ou mais erudito. O efeito catalisador de resistência ou dissidência destas culturas é ainda ilustrado pela abordagem da associação entre culturas musicais e consumos transgressivos e práticas de resistência de género. A dualidade underground/mainstream marca - como dentro de toda a esfera pop - os debates a este nivel. Também encontramos reflexões e análises centradas sobre a relação entre a transformação das práticas musicais, as tecnologias digitais e virtuais e os novos modelos de negócio, discutindo as múltiplas faces das formas de imbricação contemporânea de processos culturais/musicais, técnicos e tecnológicos, económicos e mercantis.

Estamos, assim, perante um conjunto diversificado de artigos que conjugam teoria e empiria, demonstrando a vivacidade que estes debates e questões têm alcançado na Europa do Sul e na América Latina, incluindo contributos focados em Portugal, em Espanha, em Itália e no Brasil. E esta questão é tão mais importante quanto estas são sociedades marcadas por transições e sobretudo, em tempos recentes, pela crise económica e societal, no âmbito das quais as manifestações artísticas e musicais parecem cada vez mais assumir-se como plataformas de refundação e revivificação identitárias.

Os artigos estão organizados de forma a interligar temas, desafios, abordagens e metodologias decorrentes das cenas musicais contemporâneas. No primeiro texto, justamente intitulado de "¿El declive del significado social de la música?" de Ion Andoni del Amo, Arkaitz Letamendia e Jason Diaux, problematiza-se

da Universidade do Porto (IS-UP) sob a coordenação de Paula Guerra, em parceria com o Griffith Centre for Cultural Research (GCCR), a Universitat de Lleida (UdL), a Faculdade de Economia da Universidade do Porto (FEP), a Faculdade de Psicologia e de Ciências da Educação da Universidade do Porto (FPCEUP), a Faculdade de Economia da Universidade de Coimbra (FEUC), o Centro de Estudos Sociais da Universidade de Coimbra (CES) e as Bibliotecas Municipais de Lisboa (BLX). Deste projeto e seu correlato - a KISMIF Conference - fazem parte as duas organizadoras deste número. Mais informações em www.punk.pt e http://www.kismifconference.com/pt/. Um agradecimento profundo a todos/as os/as que participaram nos vários eventos académicos associados a este projeto e cujos textos apresentaram a este número temático. 
a decadência da música fruto do avanço societal e das tecnologias e, particularmente, a capacidade da música como ritual e matriz de reestruturação identitária. Esta reflexão crucial encontra-se plasmada neste artigo através de três caminhos: uma abordagem teórica centrada nas teorias pós-subculturais; uma análise do contexto de estetização da cultura contemporânea num quadro pós-moderno; uma ilustração empírica situada na Euskal Herria e centrada na forma como os diversos agentes da música alternativa percebem o significado social da música e a sua perda de importância como matriz de socialidade comunicativa juvenil.

O artigo "Estigma, experimentação e risco: A questão do álcool e das drogas na cena punk" de Paula Guerra, Tânia Moreira e Augusto Santos Silva aborda as drogas como eixos referenciais do rock 'n' roll, em geral, e do punk rock, em particular. Assim, não será casual a reiterada presença do álcool e das drogas nos discursos dos protagonistas e nas canções do punk português. O texto não aborda o ponto de vista das práticas e contextos de consumo, mas o dos discursos elaborados, dentro da cena, sobre o sentido do uso e o risco da dependência, quer por atores punk diretamente entrevistados, quer nas letras das canções que eles consideraram como mais influentes na cena. $O$ artigo aborda três tópicos centrais: a representação da natureza da relação com o álcool e as drogas; a sua centralidade como questão identitária, isto é, respeitante ao nome, à coesão e ao posicionamento da cena; e a diversidade das atitudes e dos discursos que nela circulam.

O texto de Vincenzo Romania não sai do punk rock e mantém-se "Fedeli alla linea: CCCP and the Italian way to punk". A exemplo do que acontece com muitas cenas e subcenas musicais fora do espectro anglo-saxónico, o punk em Itália não tem sido objeto de uma larga investigação. Este artigo pretende colmatar essa questão através da análise da banda - e das letras das suas canções - CCCP - Fedeli alla linea - a mais famosa e polémica banda de punk italiano. O texto encontra fundamento na metodologia das semióticas narrativas de Greimas (1983), destacando alguns aspetos de resistência e ironia nas canções da banda $e$, simultaneamente, lançando sementes para uma comparação do punk italiano com o português e o inglês.

No artigo "Daughters of Rock and Moms Who Rock: Rock Music as a Medium for Family Relationships in Portugal", Rita Grácio discute como os processos de criação musical do rock são muitas vezes palco de prolongamento de relações familiares, designadamente assumindo os papéis das mulheres enquanto mães e filhas. Com base em dados empíricos resultantes de uma investigação em espaço português, Rita Grácio demonstra através das relações pai-filha, mãe-criança que a família e os espaços domésticos são relevantes na produção quotidiana de rock, levando a que este seja uma espécie de "family soundscape". 
Irapuan Peixoto Lima Filho centra-se no rock e no "Barulbo nas ruas escuras: Estilo de vida e redes sociais nos agrupamentos roqueiros". Este texto propõe-se analisar a formação de uma movimentação social de roqueiros na cidade de Fortaleza, capital do estado do Ceará, no Brasil. Esta movimentação vai configurar uma "rede roqueira" caracterizada por estilos e modo de vida particulares, reconfigurando-novamente - identidades.

De forma muito interessante, porque interrelacionada, Luiza Bittencourt e Daniel Domingues abordam as "Dinâmicas coletivas em cenas musicais: A experiência do Grupo \#acenavive no Rio de Janeiro". Este texto analisa as articulações do grupo de artistas que se organiza, no Rio de Janeiro, em torno da \#acenavive, utilizando o conceito de cena musical a três níveis: evidenciando o bistórico de organização conjunta promovida por esses jovens músicos, compreendendo as suas motivações e objetivos; cartografando os espaços urbanos frequentados por esses artistas e utilizados para a realização de concertos; e identificando as principais práticas culturais e de sociabilidade presentes na articulação desses jovens na sua cena.

Gil Fesch apresenta um "Rumo a uma etnografia da música contemporânea. Prólogo para um projeto de investigação". Neste artigo, o autor avança com a discussão preliminar acerca dos fundamentos teóricos que servem de base a um projeto de investigação em curso junto do Remix Ensemble Casa da Música. De âmbito teórico-metodológico, o texto oferece um quadro de análise que procura dar passos rumo a um retrato do subcampo da música contemporânea portuguesa e possibilitar uma leitura crítica da tão propalada crise da nova música.

No seguimento da crise da música mas focando-se nos seus suportes, Lucas Waltenberg desvela as "Novas configurações do álbum de música na cultura digital: O caso do aplicativo 'Biophilia'”. Este artigo aborda o processo de reestruturação da indústria fonográfica, argumentando que o formato álbum - supostamente ameaçado pelas novas práticas de consumo nas tecnologias digitais - mostra sinais de que pode ser repensado para acompanbar o processo de reestruturação da indústria musical, incentivando novas maneiras de os consumidores e os próprios artistas lidarem com a música.

No artigo intitulado "Os novos modelos de negócio da música digital e a economia da atenção", Leonardo Ribeiro da Cruz identifica e problematiza as estratégias de inserção do mercado fonográfico no ambiente digital, em especial os novos serviços gratuitos de streaming, demonstrando como estes serviços coadjuvam a ampliação da begemonia da economia da atenção online $e d a$ vigilância ubíqua e subsidiam a expansão dos espaços fechados na rede, virados para a valorização, em detrimento de espaços livres e abertos.

Finalmente, ainda no escopo das mudanças das formas de relação e artefactos musicais, Miguel Afonso Caetano apresenta o texto "Spotify e os piratas: 
Em busca de uma 'jukebox celestial' para a diversidade cultural". Ora está aqui em discussão a plataforma Spotify como "novo" veículo de acesso à música, mas sobretudo a demonstração dos principais obstáculos colocados pelos serviços comerciais de streaming apoiados pelas indústrias culturais a uma oferta centrada na diversidade cultural e na democratização do acesso à cultura.

\section{Paula Guerra e Paula Abreu}

\section{Paula Guerra}

Faculdade de Letras da Universidade do Porto Via Panorâmica, s/n, 4150-564 Porto, Portugal

Contacto: pguerra@letras.up.pt

\section{Paula Abreu}

Centro de Estudos Sociais, Universidade de Coimbra

Colégio de S. Jerónimo, Largo D. Dinis, Apartado 3087, 3000-995 Coimbra, Portugal

Contacto: pabreu@ces.uc.pt 
